\title{
O estágio na formação inicial de professores de inglês: refletindo sobre perspectivas e possibilidades
}

\author{
Julma Dalva Vilarinho Pereira Borelli \\ Universidade Federal de Mato Grosso/Universidade Federal de Goiás ${ }^{1}$
}

\begin{abstract}
Resumo
Este artigo apresenta uma discussão acerca do estágio supervisionado focalizando sua estruturação. Considerando o contexto atual e as ressignificações propostas para os estudos da linguagem (PENNYCOOK, 1990, 2001, 2010; MOITA LOPES 2006; 2013), o objetivo principal deste estudo é pensar as formas como estas mudanças estão chegando até as propostas de estágio. Para que seja possível desenvolver uma análise inicial, apresento seis artigos que focalizam o assunto para começarmos a delinear um panorama do que tem sido investigado na área. A partir do que abordam, elaboro uma breve discussão acerca dos principais pontos que poderiam ser contemplados em uma proposta de estágio alinhada aos princípios de uma atuação crítica.
\end{abstract}

Palavras-chave: Linguística Aplicada Crítica; formação de professores de línguas; estágio

\begin{abstract}
This essay presents a discussion on English teaching practicum focusing on its structure. Considering our current context and the changes proposed by language studies (PENNYCOOK, 1990, 2001, 2010; MOITA LOPES 2006; 2013), the main aim of this paper is to examine the English teaching practicum from a critical perspective. In order to develop an initial analysis, I present six articles which focus on this topic, to begin an investigation of what has been studied in the area. Based on this analysis, I present a brief discussion on the principles that could be addressed from a critical perspective of teacher education.

Keywords: Critical Applied Linguistics; language teacher education; teaching practicum
\end{abstract}

\section{INTRODUÇ̃̃O}

Em um contexto pós-moderno de reestruturação e revisão de princípios, a Linguística Aplicada Crítica (doravante LAC) ganha forças nacional e mundialmente ressignificando o trabalho do linguista, a concepção de produção de conhecimento e outros construtos que orientam para uma postura política, ética e engajada de atuação. Isso tem acontecido graças ao

\footnotetext{
${ }^{1}$ A presença de duas instituições justifica-se pelo fato de ser Professora Assistente do Departamento de Letras da Universidade Federal de Mato Grosso, campus de Rondonópolis, e, no momento de produção do artigo, ser doutoranda do Programa de Pós-Graduação em Estudos Linguísticos da Universidade Federal de Goiás.
} 
empenho de estudiosos que têm se dedicado a repensar o foco de seus estudos. Conforme esclarece Moita Lopes (2013) agimos como quem fotografa um cenário. Usamos o nosso olhar, escolhemos o nosso foco e assumimos uma perspectiva que possa promover o desenvolvimento de nossas compreensões; ampliar as nossas visões e contemplar os locais tradicionalmente marginalizados.

Essa revisão de bases inaugura o viés crítico da Linguística Aplicada e vai ressoar em suas diversas linhas de pesquisa. Aqui nos interessa, especialmente, as mudanças promovidas na formação de professores. Entendendo que a sala de aula não é um espaço neutro, mas que atende a interesses de uma organização política e social que é muitas vezes reproduzida nesse ambiente, a formação começa a prezar pela compreensão de outros elementos que constituem a situação de ensino. Dentre tais elementos temos a ideologia, as relações de poder e os interesses aos quais a nossa prática tem, consciente ou inconscientemente, servido.

Essas considerações alteram significativamente o foco dos estudos dessa linha de pesquisa. Por muitas décadas, as investigações se voltaram para a compreensão de como a aprendizagem podia ser promovida - pela utilização de métodos, pela compreensão de questões psicológicas inerentes ao ser humano, ou por ações pedagógicas de responsabilidade do professor. A orientação social da linguagem e o reconhecimento de que um trabalho crítico pode contribuir efetivamente para a melhoria de vida das pessoas aproxima a Linguística Aplicada da realidade e lhe confere novas atribuições.

Levando em conta essas mudanças, este artigo tem por objetivo pensar a organização do estágio nesse contexto. Constituindo um importante momento da formação inicial, de que maneira esses princípios têm reorientado propostas de estruturação do estágio? Em busca de um panorama que nos revele diferentes práticas de estágio, analisarei seis artigos publicados em datas posteriores a 2010, acerca de estudos desenvolvidos no Brasil. Tais artigos contemplam estudiosos de diferentes universidades brasileiras. Busco com isso iniciar uma compreensão de práticas de estágio que possam estar sendo desenvolvidas em diferentes instituições.

Reconheço que o escopo deste estudo não será suficiente para estabelecermos um panorama, contudo julgo que possa iniciar o reconhecimento de práticas locais que podem contribuir para pensarmos uma revisão do estágio. Baseada em minha própria experiência como professora de estágio e na leitura dos artigos aqui apresentados, busco discutir a importância de atribuirmos um novo olhar para o estágio, ressignificando suas práticas e o 
papel desempenhado por seus principais atores - estagiários, professores da escola e professor universitário.

Nesse intuito, inicio o artigo com uma revisão dos princípios que orientam a LAC e discuto a proposta de formação de professores nesse viés. Em seguida procedo à análise e discussão dos artigos e faço alguns apontamentos acerca dessa possível reorganização do estágio.

\section{AS CONTRIBUIÇÕES DA LINGUÍSTICA APLICADA CRÍTICA}

Refletindo sobre o compromisso da Linguística Aplicada, Pennycook (1990) destaca o compromisso social dessa ciência que, até então, não havia sido contemplado. Segundo o autor, ao reconhecermos que vivemos em mundo marcado pela diferença e desigualdade, torna-se imprescindível uma análise que nos ajude a desvelar as concepções que embasam e são reproduzidas por meio de nossas práticas. Pennycook (1990) nos convoca, assim, a uma atuação politizada, uma vez que as práticas hegemônicas cristalizadas na sociedade nos impedem de pensar maneiras alternativas de organização social.

Entendendo que a naturalização de construtos e práticas atende a interesses e reproduz ideologias dominantes, a atuação crítica se configura como uma prática problematizadora. Movidos por um compromisso moral e ético, o autor ressalta a importância de identificarmos as implicações de nossas ações, e esse reconhecimento se dá por meio do questionamento:

Qualquer abordagem sofisticada para língua e política deve inevitavelmente lidar com a tensão entre a necessidade de bases suficientemente firmes para um engajamento em ações políticas, ao mesmo tempo em que questiona as bases nas quais tais pensamentos e ações estão localizados². (PENNYCOOK, 2012, p. 130)

Problematizar significa assumir que os cenários com os quais nos deparamos não são definitivos, mas para mudá-los precisamos compreendê-los. Essa compreensão requer um olhar que vá além do que vemos superficialmente, para revelar ideologias que se materializam por meio de ações. Conforme afirma Moita Lopes (2006), as verdades geralmente revelam pontos de vista que foram favorecidos historicamente. O nosso trabalho consiste, então, em

\footnotetext{
${ }^{2}$ As traduções desta e de outras passagens de textos escritos originalmente em inglês foram feitas pela autora do artigo, no intuito de tornar a leitura mais fluida.
} 
pensar outras possibilidades de análise que partam daqueles que não contaram com tal favorecimento e foram silenciados nas margens da produção de conhecimento.

Pensando a pesquisa, Pennycook (1990) faz uma importante crítica à perspectiva positivista que orientava nossos estudos e afirma que as pesquisas em LAC devem prezar pelo entendimento e não se ocupar em apresentar provas baseadas em estatísticas. Particularmente, acredito que essa concepção de pesquisa tenha grande impacto nos avanços que temos alcançado na área. Além disso, o autor reafirma que "precisamos restabelecer a política e a ética como os principais elementos do trabalho acadêmico" (PENNYCOOK, 1990, p. 22), e buscarmos não apenas o conhecimento mais aprofundado, mas a promoção de mudanças.

Em um olhar mais recente, alinhada a essa perspectiva, Kleiman (2013) defende a reorientação das pesquisas em LA e ressalta que não se trata de fazer pesquisa "sobre" a periferia, mas "a partir dela" e com ela. A autora propõe o "suleamento" da valorização da produção de conhecimento. Isso significa que devemos deixar de reconhecer os conhecimentos que produzimos como subalternos a um centro historicamente hegemônico. Com base em Adams (2012) a autora posiciona-se favoravelmente ao engajamento político de nossas pesquisas e argumenta que

[q]ualquer que seja o sentido dado a essa inserção política, o resultado será uma construção social e epistêmica que incorpora os saberes, os modos de ser, os valores de nossos povos e que se posiciona criticamente em relação ao poder hegemônico, seja ele baseado em aspectos culturais, epistêmicos, econômicos, raciais, de gênero. (KLEIMAN, 2013, p. 45)

A autora aborda a importância de descolonizarmos o conhecimento e retoma o pensamento do sociólogo Quijano (2000) para quem um aspecto marcante da colonialidade é a negação do valor das "histórias locais". Principalmente daquelas que possam questionar a centralidade europeia e norte-americana na produção do conhecimento.

Tratando ainda dessas mudanças advindas de uma atuação crítica, Fabrício (2006, p. 49) defende

a orientação explícita para o desenvolvimento de uma agenda política, de uma agenda transformadora intervencionista e de uma agenda ética, decorrente da ideia de que nossas práticas discursivas envolvem escolhas que têm impactos diferenciados no mundo social e nele interferem de formas variadas.

É importante destacarmos que não se trata da defesa de uma imposição de mudança. Estamos pensando em um compromisso ético de um trabalho com a linguagem que contribua para a diminuição das desigualdades e para o questionamento de práticas naturalizadas. Acredito que 
isso possa nos livrar do conformismo diante da constatação de que algumas coisas "sempre foram assim".

Brevemente, a discussão desenvolvida até aqui ilustra alguns encaminhamentos da proposta crítica dos estudos linguísticos. Dedicada a pensar sobre a concepção do estágio nesse cenário, é importante que possamos vislumbrar de que forma essas ressignificações chegam à formação de professores. Sendo assim, passo a uma análise dos construtos recentes que têm orientado a formação.

\section{A FORMAÇÃO DOCENTE PELO VIÉS DA LAC}

Por se tratar de uma área em constante crescimento, a LAC tem contado com uma vasta produção. Apesar disso, Hawkins e Norton (2009) afirmam que os estudos que tratam especificamente de práticas de formação de professores em uma perspectiva crítica ainda não são muitos. Sabendo do potencial transformador da prática docente, dado, entre outros fatores, a seu acesso privilegiado a um grande número de alunos, temos que redobrar os esforços de compreensão desse contexto.

Analisando a ressignificação das propostas de formação, Hawkins e Norton (2009) afirmam que a formação crítica tem priorizado aspectos como a promoção de consciência crítica, autorreflexão crítica e relações pedagógicas críticas. A promoção de consciência crítica se refere à busca de compreensão das relações de poder que operam na sociedade, e das influências de práticas históricas, sociais e políticas na manutenção de desigualdades, dentre elas a educacional. A autorreflexão focalizaria principalmente um olhar crítico para nossas identidades e posicionamento na sociedade, considerando limitações e possibilidades de mudança. Por fim, as relações pedagógicas críticas defendem que uma prática empoderadora se constrói por meio da vivência de uma experiência educativa dessa natureza, ou seja, nossas posturas precisam ser coerentes com nossos discursos.

Ao definir a política da pedagogia como um dos temas que compõem os estudos da LAC, Pennycook (2001) reafirma a importância de reconhecermos as relações sociais e ideológicas que se estabelecem em nossas salas de aulas. Muito longe de serem espaços neutros, nossas salas tendem a reproduzir a ideologia dominante que se materializa por meio do conteúdo que trabalhamos, do material que utilizamos, da forma que usamos a língua, da maneira que avaliamos, entre outras. Refletirmos sobre a ideologia que tem orientado as 
nossas ações pode nos fortalecer para questionarmos o que nos parece injusto e motivar a busca por mudanças.

Considerando a função social da escola, o autor nos alerta para o risco de termos ali um ambiente de reprodução de injustiças, ao invés de um trabalho que vise à promoção de oportunidades igualitárias. A coexistência das forças de manutenção do interesse dominante com aquelas que buscam resistir a essa prática, fazem da escola um cenário de lutas constantes. Esse reconhecimento requer de nós um posicionamento explícito e a formação de professores não pode ignorar esses fatores. Isso não significa que responsabilizaremos os professores pela reforma social que necessitamos, mas que reconhecemos as possibilidades de ação crítica que nosso trabalho compreende. Quanto a isso, Hooks (1994, p. 206) esclarece que

[o] compromisso com uma pedagogia engajada traz com ele o desejo de ser responsável, não a pretensão de que professores não têm o poder de mudar o rumo da vida de seus alunos.

Assumir a existência dessa possibilidade condiz com a proposta de atuação transformadora da formação crítica. Complemento aqui que as possibilidades de mudança, ainda que reais, precisam coincidir com o desejo do aluno de compartilhar conosco um ideal de vida e a confiança no potencial educativo.

Nesse sentido, confesso que foi com muita simpatia que li o relato de Hooks (1994) sobre sua experiência escolar durante o período de segregação racial nos Estados Unidos. Ela afirma que muito cedo aprendeu o valor anti-hegemônico da educação. Sendo testemunha das oportunidades e possibilidades de melhoria que a educação pode promover na vida das pessoas, sempre observei com muita tristeza o desprezo com que alguns de nossos alunos tratam a passagem pela escola. Por meio das reflexões de Hooks (1994), pude entender que o próprio trabalho do professor pode convencionar esse (des)crédito dado à educação. Valendome das palavras da autora, será que nossa atuação tem sido uma prática de liberdade ou um insistente ensino à obediência? Mais uma vez entendemos a necessidade de questionar os princípios que embasam nossa docência. Para identificarmos onde estão nossos ideais, Hooks (1994, p. 21) esclarece que

[q]uando a educação é uma prática de liberdade, os alunos não são os únicos convidados a compartilhar, a confessar. A pedagogia engajada não busca simplesmente empoderar os alunos. Qualquer sala de aula que empregue um modelo holístico de aprendizagem será um lugar onde os professores crescem e são empoderados pelo processo. 
Aqui somos mais uma vez convocados a vivenciar a realidade educativa na qual acreditamos e a nos beneficiar dessa experiência.

Pensando em nossos ideais e nos princípios que orientam as nossas ações, Canagarajah (2013) apresenta um belo relato sobre os caminhos que percorreu e ainda percorre em sua prática como docente e pesquisador. $\mathrm{O}$ autor demonstra como a "política linguística é uma jornada contínua, não um estado final" (CANAGARAJAH, 2013, P. 59) e revela que em diferentes momentos sua atuação profissional foi orientada por visões de língua particulares. Cada uma dessas visões permitia uma compreensão do contexto de ensino e uma acepção do que seria o trabalho do professor. Dessa forma, o autor reafirma a parcialidade da construção ideológica, alguns fatores são enfatizados ou encobertos, mas coexistem em sua incompletude.

Isso nos faz pensar na importância do trabalho de conscientização crítica (HAWKINS, 2009) iniciado pelo formador, que deverá ser assumido pelo professor ao longo de toda a sua experiência. Analisando o papel do formador, Pennycook (2012) argumenta que formar criticamente está relacionado à busca e ao aproveitamento de pequenos momentos, em geral inesperados, para promover uma perspectiva mais crítica. O autor se refere a esses acontecimentos como momentos críticos (critical moments) e para que esses se constituam em momentos formativos é necessário que o professor saiba aproveitá-los, apesar da dinamicidade da sala de aula.

Concluindo, vemos que o encaminhamento crítico dado ao trabalho do professor promove importantes mudanças em sua atuação. Sabendo disso, é preciso pensar de que maneira a sua formação poderá iniciá-lo nesse processo. Iniciá-lo porque acredito que a construção da prática se dará prioritariamente em sua atuação profissional diária. Dessa forma, entendo que as ressignificações ocorridas na LA e na perspectiva de formação docente que as encaminham para um posicionamento crítico, requeiram um novo olhar para o estágio. É justamente a essa discussão que nos dedicamos agora.

\section{ESTUDOS SOBRE O ESTÁGIO: DELINEANDO PERSPECTIVAS E DISCUTINDO POSSIBILIDADES}

Nesta seção apresento alguns artigos publicados no Brasil que focalizam o estágio na formação do professor de inglês. Dentre os recortes que estabeleço para seleção dos artigos defino os seguintes critérios: a) tratar da formação de professores de língua inglesa; b) estar na 
área de LA; c) ser publicado no Brasil e d) datar de 2010 até o momento. Delimitar a língua estrangeira justifica-se pelas especificidades que o ensino dessa língua carrega, por exemplo, seu caráter hegemônico. O foco na LA, além do fato de que esta compreende a área de estudos de línguas estrangeiras, dá-se pela amplitude de estudos desenvolvidos na área da educação que, apesar de iluminarem nossas compreensões, não focalizam o ensino de línguas estrangeiras. Optei por trabalhos recentes publicados no Brasil por intencionar estabelecer um panorama dos estudos atuais sobre o estágio e os temas que têm abordado.

Tendo o intuito de delinear neste momento um breve panorama desses estudos, o foco desta seção será apresentar o que alguns estudiosos têm se dedicado a compreender acerca desse assunto. Sendo assim, não me interessa o desenvolvimento de uma análise ou mesmo comentários críticos acerca do que discutem ou da forma que fazem tal abordagem. Procuro apresentar de forma sucinta o foco de cada pesquisa e essa análise constitui um estudo piloto de parte de minha pesquisa de doutorado. Compreender o que tem sido feito nesta área de estudo pode nos ajudar a pensar sobre a organização do estágio, que é o meu principal objetivo.

O primeiro artigo que apresento é intitulado $O$ estágio de observação como espaço de complexidade, de autoria da professora $\operatorname{Dr}^{\mathrm{a}}$ Maximina M. Freire, da Pontifícia Universidade Católica de São Paulo (PUC-SP). Esse artigo foi publicado em 2011 e apresenta uma análise feita pela supervisora de estágio acerca da primeira etapa do estágio, a observação. Sua reflexão sobre a construção de significados a respeito do papel da observação e de seu de seu próprio papel de formadora é embasada pelas teorias da complexidade (Morin, 2005; Moraes, 2002, 2010) e do pensamento sistêmico (Tescarolo, 2005; Morin, 2008). Em suas considerações, a autora reitera a importância do estágio de observação pela inserção do estudante no contexto de ensino e reflexões que ele promove. Ressalta também o papel fundamental da supervisora de estágio que promove a mediação dos conteúdos trazidos para reflexão com as outras disciplinas do curso e gerencia os momentos de (des)estabilização característicos dessa experiência.

O segundo artigo sobre o qual discorro é $A$ condição de aluno-professor de língua Inglesa em discussão: estágio, identidade e agência, das autoras Clarissa Menezes Jordão e Édina Aparecida Cabral Bührer, da Universidade Federal do Paraná (UFPR), publicado em 2013. As autoras focalizam as situações conflitantes geradas pelo papel híbrido, ora aluno ora professor, desempenhado pelos estagiários. Discutem também como a ressignificação pósmoderna do conceito de identidades fragmentadas e múltiplas pode ajudar os alunos a se 
desapegarem dos binarismos e a assumirem a coexistência de diferentes papéis. Apoiadas em autores como Bhabha, Hall e Derrida, as autoras esclarecem que o reconhecimento desse lugar de hibridização pode oportunizar o exercício da agência por parte dos estagiários por meio de um posicionamento consciente. Sendo assim, concluem caracterizando o estágio curricular supervisionado como um espaço de conflitos que, ao invés de gerar tristezas, motivam o crescimento pessoal e profissional.

O terceiro artigo, da professora Viviane Pires Viana Silvestre, da Universidade Estadual de Goiás, tem como título Estágio Supervisionado: reflexões de alunos-professores de língua estrangeira e foi publicado em 2011. Em seu texto a autora relata diferentes práticas reflexivas desenvolvidas com os alunos e focaliza suas trajetórias como aprendizes, seus desempenhos na disciplina, suas concepções sobre o contexto em que realizariam o estágio e suas percepções acerca das estratégias utilizadas para promover os momentos reflexivos. Nas reflexões finais de seu artigo a autora ressalta a avaliação positiva feita pelos alunos acerca da experiência de reflexão mediada por diferentes instrumentos, e a importância de promover momentos para que os alunos avaliem o seu próprio desempenho. Além disso, a autora relata que os alunos sentem-se desmotivados ao terminarem o estágio de observação, porém, impelidos a promover um ensino diferente.

O quarto artigo, Entretecendo vozes na (re)escrita de diários reflexivos de professores de línguas em formação inicial, da autora Cristiane Carvalho de Paula Brito, foi publicado em 2012. Brito (2012) apresenta uma análise, em interface com a Análise do Discurso de linha francesa, dos diários de alunos buscando compreender suas representações acerca desse gênero. $\mathrm{O}$ foco está na reescrita dos diários mediante as intervenções da supervisora. Além disso, a autora problematiza o papel desse instrumento de formação e o papel da escrita nesse processo. Autora advoga por uma aproximação entre a LA e Análise do Discurso de linha francesa para uma ampliação da compreensão do fenômeno linguístico. Em suas palavras finais a autora apresenta o diálogo, na concepção bakhtiniana, como possibilidade de trans-formação e ressalta os aspectos positivos dessa interação promovida pela escrita-intervenção-reescrita dos diários.

$\mathrm{O}$ quinto artigo que abordo intitula-se Análise das experiências da disciplina de estágio supervisionado do curso de Letras em Curitiba, das autoras Dinamara Pereira Machado, Paula Cristina Reis e Siderly do Carmo Dahle de Almeida Barbosa, da Faculdade Regional Santa Cruz de Curitiba (FARESC), e foi publicado em 2012. Neste estudo as autoras relatam uma experiência de estágio em um programa das escolas municipais, o que permitia 
que o estágio fosse cumprido em um horário alternativo, por exemplo, nos finais de semana. Isso, segundo as autoras, amplia as possibilidades de realização do estágio, já que muitos alunos de Letras são trabalhadores, e permite um atendimento das necessidades da comunidade participante do projeto.

O sexto e último artigo a ser apresentado é de autoria de Raquel Gamero e Vera Lúcia Lopes Cristóvão, foi publicado em 2013 e intitula-se $A$ construção de identidade profissional no estágio de regência de inglês. Nesse artigo, as autoras revelam que o estágio de regência ocorre em um ambiente não tradicional, em que uma postura colaborativa é estabelecida entre os participantes. $\mathrm{O}$ foco do estudo é o estágio de regência e não temos detalhes da primeira etapa, contudo o relato das professoras nos deixa inferir que a regência sucede uma etapa de observação e reflexão.

Os estudos apresentados nos revelam que o estágio tem recebido a atenção de estudiosos da LAC, os quais têm se dedicado a compreender diferentes aspectos que o compõem. Nesses poucos estudos temos exemplos que contemplam a importância do estágio de observação; a identidade do aluno formando; a análise de instrumentos formativos, como as práticas reflexivas e a escrita de diários; e a reflexão sobre experiências localizadas de estágio. O que me chama a atenção, especificamente, é o fato de ainda não termos questionado ou proposto uma revisão que focalize a estrutura do estágio, ou seja, sua organização em estágio de observação e estágio de regência.

Minhas reflexões acerca da estrutura do estágio são motivadas pela minha prática como professora de estágio supervisionado. Em geral, os alunos se mostravam muito desmotivados com as situações de sala de aula que presenciavam - pouco interesse dos alunos, conversas, desmotivação do professor, pequena carga horária da disciplina. Particularmente, eu não concebo a observação como sendo um bom início para o estágio. $\mathrm{O}$ pouco envolvimento do aluno com a situação de ensino lhe confere um olhar de julgamento que, muitas vezes, tende a ressaltar os problemas da situação que observa.

Tomando por base o estágio de observação, discuto então as minhas inquietações no que diz respeito ao papel dos estagiários, do professor da escola e ao meu papel de professora universitária. Sei que hoje o estágio assume diferentes configurações dependendo da instituição de formação que o promove. Insisto, contudo, na discussão desta experiência local por entender que ela pode, ainda, encontrar espaços em que as reflexões apresentadas aqui façam sentido e possam contribuir para a desestabilização de posturas assumidas durante esse período de formação. 
Apesar de as etapas do estágio estarem definidas por lei (CNE/CP 01 - 2002), acredito na importância de repensarmos uma reorganização deste período que tome por princípio uma redefinição de etapas e papéis. Acredito que se o estagiário iniciar seu trabalho se envolvendo, ainda que minimamente, com o trabalho do professor, sua visão poderá ser mais positiva ou até mesmo mais crítica. Mudar a perspectiva de análise de quem participa ou apenas observa pode modificar a percepção dos estagiários. Acredito que aprender a ensinar esteja muito mais relacionado a aprender a envolver-se do que a aprender a observar o que não nos diz respeito. Além disso, eles têm a oportunidade de começar a experienciar efetivamente a identidade de professores, como argumentam Jordão e Bührer (2013), que é um elemento importante do estágio.

Pensando em como o estágio é instituído nas escolas, sabemos que nem sempre o professor tem autonomia para decidir sobre a presença ou não de estagiários em sua sala, podendo essa decisão estar a cargo da coordenação. Ter em nossa sala a presença de um estagiário que observa e toma notas, me parece uma postura desconfortável e pouco respeitosa com o profissional que nos abre as portas de sua sala. Reconheço que, ao assinar os formulários de observação, o professor tem acesso às anotações dos estagiários; contudo, a dinamicidade do dia-a-dia nem sempre permite que isso ocorra. $\mathrm{Na}$ maioria das vezes o professor não dispõe de tempo para que possa olhar cuidadosamente e questionar os apontamentos feitos sobre sua prática. Dessa forma, o estágio me parece esvaziado de sentido.

Além do estagiário, precisamos repensar o papel do professor da escola. Reconsiderando sua identidade no contexto de estágio, esse professor é um parceiro formador de nossos alunos. A eles confiamos a apresentação dos contextos em que nossos alunos atuarão. Sendo assim, acredito em uma parceria colaborativa desses dois polos formadores escola e universidade. Ressalto aqui que a aproximação dessas instituições se dará pelo trabalho desempenhado por seus professores e pelo conhecimento que serão capazes de produzir conjunta e colaborativamente. É muito importante que o professor da escola se sinta e seja visto como alguém que tem um conhecimento a ser partilhado e saiba que esse conhecimento é valorizado pela universidade e pelos novos profissionais. Da mesma forma, é relevante que esses docentes sintam que também podem aprender e se beneficiar desse processo.

No que diz respeito ao professor universitário, e aqui tomo por base minha própria prática, há um distanciamento deste profissional do contexto em que a observação acontece. Pensando na importância deste "primeiro" contato dos alunos como aprendizes de uma 
profissão, a participação e orientação do professor de estágio poderia ter um caráter mediador. É nesse sentido que acredito que uma atuação colaborativa poderia contribuir para a melhoria do estágio. Um momento de preparação poderia tornar esta experiência mais significativa e mais produtiva para aqueles que participam deste processo.

Concluindo, acredito que uma reestruturação do estágio, que reveja não apenas suas etapas, mas também o papel daqueles que o desenvolvem, possa contribuir para uma formação mais crítica de nossos alunos. Tal reestruturação depende de um maior envolvimento e participação daqueles que atuam neste cenário. Precisamos nos aproximar das escolas, criar laços entre os trabalhos que desenvolvemos, desejar contribuir com aquele contexto que participa da formação de nossos alunos. Em outras palavras, precisamos nos envolver mais com a formação que desejamos promover para os nossos alunos - mero cumprimento de burocracias ou oportunidade significativa de compreensão da profissão?

Volto minhas reflexões neste artigo ao estágio de observação, mas defendo que o estágio, de maneira geral, pode se beneficiar dessa revisão de papéis e de uma reorganização que não separe tão sistematicamente observação e regência.

\section{CONSIDERAÇÕES FINAIS}

Busco com este artigo problematizar o estágio por um viés específico, sua estruturação. Por estruturação entendo não apenas a sua organização em etapas - observação e regência, mas uma configuração de papéis que engloba o professor universitário, o professor da escola e os estagiários. Isso implica uma reconsideração da atuação de cada participante que, em linhas gerais, poderíamos dizer que abrange uma maior valorização dos saberes do professor da escola e seu reconhecimento como agente formador de nossos alunos, bem como um maior envolvimento por parte dos estagiários e professor universitário.

Essa perspectiva de reestruturação alinha-se aos princípios de uma formação crítica que permite aos alunos elaborar considerações que ultrapassem o âmbito da sala de aula. Conforme discutimos, a postura crítica envolve o questionamento de práticas estabelecidas em prol de uma atuação que priorize a ética e o ideal transformador como orientadores de nossas ações. Como bem nos lembra Freire (citado por Norton e Hawkins, 2009) nossos alunos precisam experimentar práticas emancipatórias se desejamos formá-los para a 
transformação. Não basta dizermos o que devem fazer, eles precisam vivenciar essas práticas em sua formação.

É importante ressaltar que, ao argumentar em favor de uma ressignificação do estágio, não estou supondo que haja uma homogeneização de práticas que não possam romper com sua organização tradicional. No entanto, uma vez que estamos orientados por lei ( $\mathrm{CNE} / \mathrm{CP}$ 01-2002), acredito na relevância de discutirmos como esta prática tem sido desenvolvida e a importância de uma revisão que priorize os construtos que encaminham para uma atuação crítica.

Por fim, o cenário atual da Linguística Aplicada tem nos convidado à ressignificação de uma série de práticas naturalizadas. Conforme afirma Moita Lopes (2013) trata-se de atendermos o desafio de mudar o nosso foco e, mais do que isso, de entender que existem ângulos que o nosso posicionamento não consegue alcançar. São outras pessoas, de lugares diferentes, que poderão iluminar a nossa compreensão, contemplando fatores que precisam ser priorizados. A ressignificação discutida neste artigo é uma dessas tentativas de trazer outras vozes para "dizer" o estágio, contribuindo para que ele se torne um espaço mais democrático de construção de conhecimento.

\section{REFERÊNCIAS}

BRITO, C. C. de P. Entretecendo Vozes na (Re)Escrita de Diários Reflexivos de Professores de Línguas em Formação Inicial. Signum: Estud. Ling., Londrina, n. 15/2, p. 65-83, dez. 2012.

CANAGARAJAH, S. Navigating language politics: a story of critical praxis. In: NICOLAIDES, C.; SILVA, K. A. da S.; TÍLIO, R.; ROCHA, C. H. (Org.) Política e políticas linguísticas. Campinas: Pontes, 2013, p. $43-61$.

FABRÍCIO, B. F. Linguística aplicada como espaço de desaprendizagem: redescrições em curso. In: MOITA LOPES, L. P. (Org.). Por uma linguística aplicada indisciplinar. São Paulo: Parábola, 2006, p. 45-63.

FREIRE, M. O estágio de observação e a formação docente sob a perspectiva da complexidade. In: SILVA, K. A. da; DANIEL, F. de G.; KANEKO-MARQUES, S. M.; SALOMÃO, A. C. B. (Org.). A formação de professores de línguas: novos olhares. vol.1. São Paulo: Pontes, 2001.

GAMERO, R.; CRISTOVÃO, V. L. A construção de identidade profissional no estágio de regência de inglês. Revista Eletrônica Pro-docência/UEL. Ed. No 3, vol. 1, jan-jun. 2013. Diponível em: http://www.uel.br/revistas/prodocenciafope. Acesso em: 06/08/2014. 
HAWKINS, M.; NORTON, B. Critical language teacher education. In: BURNS, A.; RICHARDS, J. (Eds.). Cambridge guide to second language teacher education. Cambridge: CUP, 2009, p. 30-39.

HOOKS, B. Teaching to transgress: education as the practice of freedom. New York: Routledge, 1994

JORDÃO, C. M.; BÜHRER, E. A. C. A condição de aluno-professor de língua inglesa em discussão: estágio, identidade e agência. Educação e Realidade. Porto Alegre, v. 38, n. 2, p. 669-682. abr./jun. 2013. Disponível em:

http://seer.ufrgs.br/educacaoerealidade/article/view/23490. Acesso em: 06/08/2014.

KLEIMAN, A. B. Agenda de pesquisa e ação em Linguística Aplicada: problematizações. In: LOPES, L. P. da M. (Org.). Linguística Aplicada na modernidade recente: Festschrift para Antonieta Celani. São Paulo: Parábola Editorial, 2013, p. 38-58.

MACHADO, D. P.; REIS, P. C.; BARBOSA, S. do C. D. de A. Análise das experiências da disciplina de Estágio Supervisionado do curso de Letras em Curitiba. Anais do IX Anped Sul Seminário de Pesquisa em Educação da Região Sul, 2012. Disponível em:

http://www.ucs.br/etc/conferencias/index.php/anpedsul/9anpedsul/paper/viewFile/803/87. Acesso em: 06/08/2014.

MOITA LOPES, L. P. Linguística aplicada e vida contemporânea: problematização dos construtos que têm orientado a pesquisa. In: MOITA LOPES, L. P. (Org.). Por uma lingüística aplicada indisciplinar. São Paulo: Parábola, 2006, p. 85-105.

Fotografias da Linguística Aplicada brasileira na modernidade recente: contextos escolares. In: MOITA LOPES, L. P. (Org.). Linguística Aplicada na modernidade recente: festschrift para Antonieta Celan. São Paulo: Parábola, 2013, p. 15-38.

PENNYCOOK, A. Towards a critical Applied Linguistics for the 1990s. Issues in Applied Linguistics, 1, 8-28.

- Critical Applied Linguistics: a critical introduction. Mahwah NJ: Lawrence Erlbaum Associates, 2001.

. Language as a local practice. London: Routledge, 2010.

2012.

. Language and mobility: unexpected places. Bristol: Multilingual Matters,

SILVESTRE, V. P. V. Estágio Supervisionado: reflexões de alunos-professores de língua estrangeira. Anais do SILEL. Volume 2, Número 2. Uberlândia: EDUFU, 2011. Disponível em: http://www.ileel2.ufu.br/anaisdosilel/wp-content/uploads/2014/04/silel2011 1405.pdf.

Acesso em: 06/08/2014. 


\section{A AUTORA}

Julma Dalva Vilarinho Pereira BORELLI é professora da Universidade Federal de Mato Grosso, campus de Rondonópolis, onde atua no curso de Letras-Língua Inglesa. Tem mestrado em Letras e Linguística pela Universidade Federal de Goiás (2006) e desde 2014 é aluna de doutorado do Programa de Pós-Graduação em Letras e Linguística da Universidade Federal de Goiás (UFG), sob orientação da $\operatorname{Prof}^{a} \operatorname{Dr}^{a}$ Rosane Rocha Pessoa. Seu principal interesse de pesquisa é a formação crítica de professores de línguas.

E-mail: julmaborelli@gmail.com 